Check for updates

1 University of Birmingham, Birmingham, UK

2 University of Leicester. Leicester, UK

3 Newcastle University, Newcastle, UK

Correspondence to: J Deeks

J.Deeks@bham.ac.uk

Cite this as: BMJ 2020;370:m3699 http://dx.doi.org/10.1136/bmj.m3699

Published: 22 September 2020

\title{
Operation Moonshot proposals are scientifically unsound
}

\author{
They could do more harm than good to people, populations, and the economy \\ Jonathan J Deeks, ${ }^{1}$ Anthony J Brookes, ${ }^{2}$ Allyson M Pollock ${ }^{3}$
}

The polymerase chain reaction (PCR) swab test is useful (but not perfect) for detecting SARS-CoV-2 virus RNA in symptomatic patients. ${ }^{1}$ However, problems arise using the test for purposes that disregard symptoms or time of infection-namely, case finding, mass screening, and disease surveillance.

This is because PCR is not a test of infectiousness. Rather, the test detects trace amounts of viral genome sequence, which may be either live transmissible virus or irrelevant RNA fragments from previous infection. ${ }^{2}$ When people with symptoms or who have been recently exposed receive a positive PCR result they will probably be infectious. But a positive result in someone without symptoms or known recent exposure may be from live or dead virus, and so does not determine whether the person is infectious and able to transmit the virus to others. ${ }^{3}$

The PCR “cycle threshold” $(\mathrm{Ct})$ value provides an estimate of the quantity of target RNA in the swab sample. It correlates with symptoms, ${ }^{4}$ and people with low Ct values (indicating more viral material) are those most likely to be infectious. ${ }^{5}$ Using a low maximum Ct value (around $30^{56}$ ) has been suggested to reduce problematic detection of dead virus, ${ }^{6}$ but it will also miss early infection and rising infectiousness in both presymptomatic and symptomatic people. The measurement error of $\mathrm{Ct}$ values is non-trivial, and measurements vary between manufacturers and laboratories. ${ }^{7}$ Thus it is impossible to define a universally optimal Ct value for reliable identification of those who are infectious.

If PCR is used to identify cases through mass testing of healthy people, it will deliver positive results in individuals with previous resolved infections, new infections, and potential re-infections, as well as false positives in people genuinely not harbouring the virus (around $0.8 \%$ of all tests performed ${ }^{8}$ ). Identifying the truly infectious-who must isolate-is not straightforward, even with a clinical history. For example, between $4 \%$ and $41 \%$ of cases are asymptomatic, with a risk of transmission roughly half that of symptomatic cases, ${ }^{9}$ but a positive test in those with no history of symptoms could indicate either current infection or previously resolved asymptomatic infection.

Real concern exists that many people who are not infectious (and not likely to become infectious) will receive positive test results, and together with their contacts, will be forced to isolate unnecessarily. In the context of mass surveillance, this could be a majority of those who test positive. Using PCR for population screening-even with a lower maximum $\mathrm{Ct}$ value cut off-is not epidemiologically sound. The balance of costs and harms against the potential benefits has not been evaluated

\section{Testing conundrums}

Now, Operation Moonshot has proposed that mass screening with less accurate point-of-care tests will help "reduce the ' $R$ ' rate, keep the economy open and enable a return to normal life." ${ }^{10}$ Could this work?

The Moonshot proposals are based exclusively on computer modelling ${ }^{11}$ not empirical evidence. Critically, the model considers repeated use of tests that are positive only in infected people with high viral loads of SARS-CoV-2. The crux of the assumptions in the Moonshot modelling is that the test must have a high chance of being positive when a person is infectious and a low chance when they are not. ${ }^{11}$ Thus, although the proposed test has lower sensitivity than PCR for detecting any infection with SARS-CoV-2, it must have equal sensitivity for detecting infections that could be passed on to others.

It is inappropriate to describe a test with these properties as "less accurate"- a description that has allowed some companies to launch suboptimal products, ${ }^{12}$ possibly encouraged by the magnitude of government contracts, low levels of government scrutiny, and the lack of an effective regulatory process for diagnostic tests. ${ }^{13}$

Frequent repeat testing is necessary as the proposed test will only identify people with new infections when their viral load becomes high. Since Moonshot proposes use of point-of-care tests, delays in receiving results would be eliminated and isolation can be immediate. But no point-of-care tests approved for home use are currently available.

One fundamental challenge is that proper evaluation of any point-of-care test destined for mass screening requires a robust and reliable way to identify true infectiousness: we need a reference standard against which the new test's performance can be compared. Viral culture is one option, but culture based tests are hard to run and have high failure rates. ${ }^{5}$

The Moonshot proposals have been condemned for not considering the potential harms from repeated frequent testing of whole populations. ${ }^{12}$ All tests generate some false positives and false negatives. The consequences of high false negative rates are most serious in symptomatic people who can transmit disease. Up to $30 \%$ of people with SARS-CoV-2 infection are missed by swab based PCR testing, for example. ${ }^{14}$

False positives become a problem when individuals and their contacts have to self-isolate unnecessarily. Even with a specificity of $99 \%$, proposals to do 10 million tests a day will generate many thousands of 
false positive results, causing unnecessary but legally enforced isolation of both cases and contacts with potentially damaging consequences for the UK economy and for civil liberties.

Competing interests: We have read and understood BMJ policy on declaration of interests. JD leads the Cochrane covid-19 test evaluation reviews and is a member of the Royal Statistical Society covid-19 task force steering group. AP is a member of independent SAGE.

Provenance and peer review: Commissioned; not externally peer reviewed.

1 Holborow A, Asad H, Porter L, etal. The clinical sensitivity of a single SARS-CoV-2 upper respiratory tract RT-PCR test for diagnosing COVID-19 using convalescent antibody as a comparator. Clin Med (Lond) 2020;clinmed.2020-0555. doi: 10.7861/clinmed.2020-0555 pmid: 32917746

2 Atkinson B, Petersen E. SARS-CoV-2 shedding and infectivity. Lancet 2020;395:1339-40. doi: 10.1016/S0140-6736(20)30868-0 pmid: 32304647

3 Quicke K, Gallichote E, Sexton N, et al. Longitudinal surveillance for sars-cov-2 rna among asymptomatic staff in five colorado skilled nursing facilities: epidemiologic, virologic and sequence analysis. medRxiv 2020.06.08.20125989. [Preprint.] doi: 10.1101/2020.06.08.20125989

4 Huang C-G, Lee K-M, Hsiao M-J, etal. Culture-based virus isolation to evaluate potential infectivity of 355 clinical specimens tested for covid-19. J Clin Microbiol 2020;58:e01068-20. doi: 10.1128/JCM.01068-20 pmid: 32518072

5 Jefferson T, Spencer E, Brassey J, Heneghan C. Viral cultures for COVID-19 infectivity assessment. Systematic review. medRxiv 2020.08.04.20167932. [Preprint.] doi: 10.1101/2020.08.04.20167932

6 Tom MR, Mina MJ. To interpret the SARS-CoV-2 test, consider the cycle threshold value. Clin Infect Dis 2020;ciaa619. doi: 10.1093/cid/ciaa619. pmid: 32435816

7 van Kasteren PB, van der Veer B, van den Brink S, etal. Comparison of seven commercial RT-PCR diagnostic kits for COVID-19. J Clin Virol 2020;128:104412. doi: 10.1016/j.jcv.2020.104412 pmid: 32416600

8 Cohen AN, Kessel B, Milgroom MG. Diagnosing COVID-19 infection: the danger of over-reliance on positive test results. medRxiv 2020. [Preprint.] doi: 10.1101/2020.04.26.20080911.

9 Byambasuren O, Cardona M, Bell K, Clark J, McLaws M-L, Glasziou P. Estimating the extent of asymptomatic COVID-19 and its potential for community transmission: systematic review and meta-analysis. medRxiv 2020.05.10.20097543. [Preprint.] doi: 10.1101/2020.05.10.20097543

10 lacobucci G, Coombes R. Covid-19: Government plans to spend $£ 100 \mathrm{bn}$ on expanding testing to 10 million a day. BMJ2020;370:m3520. doi: 10.1136/bmj.m3520 pmid: 32907851

11 Larremore DB, Wilder D, Lester E, et al. Test sensitivity is secondary to frequency and turnaround time for COVID-19 surveillance. medRxiv 2020. [Preprint.] doi: 10.1101/2020.06.22.20136309

12 Gross A, KellyJ. Is the company with a 20-second coronavirus test for real? Financial Times 2020 Sep 16, https://www.ft.com/content/e7a279df-3239-4e00-be29-f38d98f4d730.

13 Allan C, Joyce TJ, Pollock AM. Europe's new device regulations fail to protect the public. BMJ 2018;363:k4205. doi: 10.1136/bmj.k4205 pmid: 30305299

14 Arevalo-Rodriguez I, Buitrago-Garcia D, Simancas-Racines D, et al. False-negative results of initial RT-PCR assays for Covid-19: a systematic reviews. medRxiv 2020.04.16.20066787. [Preprint.]; doi: 10.1101/2020.04.16.20066787

This article is made freely available for use in accordance with BMJ's website terms and conditions for the duration of the covid-19 pandemic or until otherwise determined by BMJ. You may use, download and print the article for any lawful, non-commercial purpose (including text and data mining) provided that all copyright notices and trade marks are retained. 